Jpn. J. Infect. Dis., 71, 58-61, 2018

Short Communication

\title{
Detection and Serotyping of Dengue Viruses in Aedes aegypti and Aedes albopictus (Diptera: Culicidae) Collected in Surabaya, Indonesia from 2008 to 2015
}

\author{
Kris Cahyo Mulyatno ${ }^{1,2 *}$, Tomohiro Kotaki ${ }^{1,4,5}$, Subagyo Yotopranoto ${ }^{2,3}$, Etik Ainun Rohmah ${ }^{2}$, Siti Churotin ${ }^{1,2}$, \\ Teguh Hari Sucipto ${ }^{1,2}$, Ilham Harlan Amarullah², Puspa Wardhani ${ }^{2,3}$, Soegeng Soegijanto ${ }^{2,3}$, \\ and Masanori Kameoka ${ }^{1,4,5}$ \\ ${ }^{I}$ Indonesia-Japan Collaborative Research Center for Emerging and Re-emerging Infectious Diseases, Institute \\ of Tropical Disease, Airlangga University, Surabaya; \\ ${ }^{2}$ Institute of Tropical Disease, Airlangga University, Surabaya; \\ ${ }^{3}$ Faculty of Medicine, Airlangga University, Surabaya, Indonesia; \\ ${ }^{4}$ Center of Infectious Diseases, Kobe University Graduate School of Medicine, Hyogo; and \\ ${ }^{5}$ Department of International Health, Kobe University Graduate School of Health Sciences, Hyogo, Japan
}

\begin{abstract}
SUMMARY: Aedes aegypti and Aedes albopictus are the primary and secondary vectors, respectively, of dengue, the most important arboviral disease in the world. The aim of this study was to detect and serotype dengue viruses (DENV) in the vectors Ae. aegypti and Ae. albopictus in Surabaya, Indonesia. Between 2008 and 2015, 16,605 Aedes mosquitoes were collected in 15 sub-districts of Surabaya. Ae. aegypti was dominant (90.9\%), whereas few Ae. albopictus were collected (9.1\%). A total of 330 pools of adult Aedes mosquitoes were subjected to the serotyping of DENV by RT-PCR. DENV-1 (52.3\%) was the most frequently detected serotype, followed by DENV-2 (40.3\%), DENV-4 (4.6\%), and DENV-3 (2.8\%). The average minimum infection rate for Ae. aegypti in various sub-districts of Surabaya was 7.2 per 1,000 mosquitoes, while that for Ae. albopictus was 0.7 per 1,000 mosquitoes. The results showed that the predominantly circulating DENV serotype in mosquitoes continuously shifted from DENV-2 (2008) to DENV-1 (2009-2012), to DENV-2 again (2013-2014), and then back to DENV-1 (2015). The circulating DENV serotypes in mosquitoes were generally consistent with those in humans. Therefore, the surveillance of infected mosquitoes with DENV might provide an early warning sign for the risk of future dengue outbreaks.
\end{abstract}

Dengue fever and dengue hemorrhagic fever, or dengue and severe dengue, are globally important arboviral diseases with a 30 -fold increase being reported in the number of human cases in the last 50 years $(1,2)$. Endemicity for dengue is also expanding to denguefree countries, including Japan $(1,3)$. The estimated number of annual dengue cases ranges between 50 and 100 million, with approximately 2.5 billion individuals being at risk, $75 \%$ of whom are located in the South East Asian and the Pacific regions (1).

Dengue virus (DENV) comprises 4 genetically and antigenically distinct serotypes (DENV-1, DENV-2, DENV-3, and DENV-4). DENV is transmitted by mosquitoes belonging to the genus Aedes, particularly Ae. aegypti and Ae. albopictus. The dynamics of dengue outbreaks is complex and characterized by the frequent replacement of virus lineages and serotypes (4). The exact mechanism for this replacement is still unknown;

Received March 15, 2017. Accepted August 17, 2017.

J-STAGE Advance Publication October 31, 2017.

DOI: 10.7883 /yoken.JJID.2017.117

*Corresponding author: Mailing address: Indonesia-Japan Collaborative Research Center for Emerging and Reemerging Infectious Diseases, Institute of Tropical Disease, Airlangga University, J1, Mulyorejo, Surabaya 60115, Indonesia. Tel/Fax: +62-31-594-0917, E-mail: kriscahyo@ staf.unair.ac.id however, purifying selection by host immune responses (5), lineage bottlenecks, and environmental impacts on the mosquito populations were found to be the key factors involved in the replacement of viral lineages and serotypes (6).

Indonesia is a tropical country that is hyperendemic to dengue, wherein all the 4 DENV serotypes have been circulating. Dengue cases have been reported in all the 34 provinces in Indonesia throughout the year, and outbreaks occur periodically (7). Surabaya is the second largest city of Indonesia. Previous studies on the isolation of DENVs from human sera indicated that serotype shifts from DENV-2 to DENV-1 occurred in 2008 , followed by the replacement from DENV1 to DENV-2 in 2013 in Surabaya $(8,9)$. However, epidemiological surveys of DENV, particularly, the detection of DENVs in Aedes mosquitoes, are limited in Indonesia. Therefore, in this study, we performed the detection and serotyping of DENV in Aedes mosquitoes collected from the dengue endemic sub-districts of Surabaya, Indonesia.

Adult mosquitoes were collected between 2008 and 2015 from 15 sub-districts (Tegalsari, Simokerto, Sukomanunggal, Tandes, Asemrowo, Kenjeran, Bulak, Tambaksari, Gubeng, Sukolilo, Rungkut, Mulyorejo, Dukuh Pakis, Sawahan, and Wonocolo) of Surabaya, Indonesia $\left(17^{\circ} 15^{\prime} 55^{\prime \prime} \mathrm{S} ; 112^{\circ} 44^{\prime} 33^{\prime \prime} \mathrm{E}\right)$, which reported confirmed dengue cases. Aedes spp. were collected 
from the houses of the residents diagnosed with dengue fever and from another 5 residences (neighboring houses) adjacent to the dengue patient house. Adult mosquitoes were captured indoors and outdoors using yeast-generated $\mathrm{CO}_{2}$ traps and sweep nets. The collected mosquitoes were freeze-killed at $-30^{\circ} \mathrm{C}$ and sorted by species, date, and location. Male and female mosquitoes were distinguished based on the morphological differences of their antennae. All adult female Aedes mosquitoes were pooled (primarily 30-50 individuals/pool) and then subjected to RNA extraction using the QIAamp Viral Mini Spin Kit (Qiagen, Hilden, Germany). The presence of viral RNA was confirmed by RT-PCR (10). Briefly, viral RNA was reverse transcribed to cDNA using the SuperScript III First-Stand Synthesis Kit (Invitrogen, Carlsbad, CA, USA) with the reverse primer, D2 (5'TTGCACCAACAGTCAATGTCTTCAGGTTC-3'). DENV-1, DENV-2, DENV-3, and DENV-4 genomes

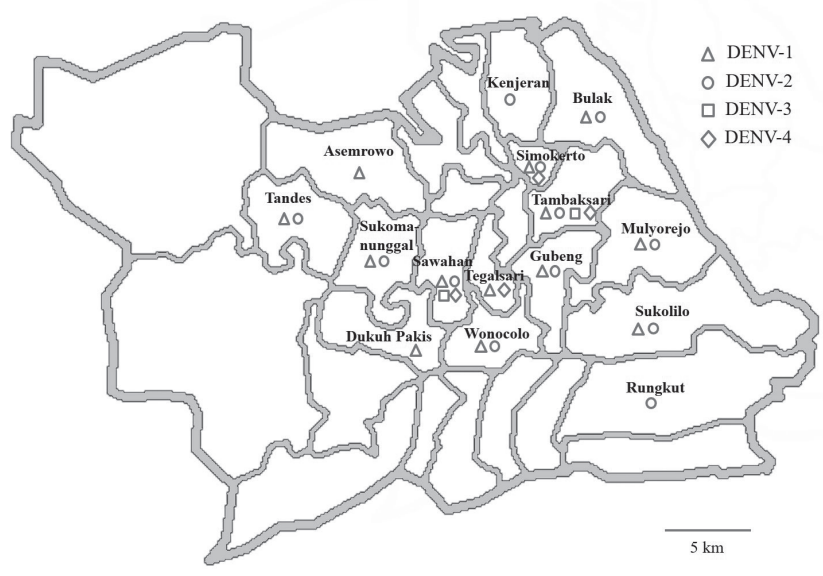

Fig. 1. Geographic distribution of DENV detected from Aedes mosquitoes in sub-districts of Surabaya between 2008 and 2015. were amplified by a multiplex PCR using rTaq (Toyobo, Osaka, Japan), along with the sense primer D1 (5'-TCAATATGCTGAAACGCGCGAGAAACCG-3') and the serotype specific reverse primers (TS1: $5^{\prime}$ - CGTC T CAGTGAT C CGGGGG-3 '; T S 2 : $5^{\prime}$ - CGCCACAAGGGCCATGAACAG-3'; TS 3 : 5'-TAACATCATCATGAGACAGAGC-3'; and TS4: 5'-CTCTGTTGTCTTAAACAAGAGA-3') to generate 482, 118, 290, and 392-bp fragments, respectively. The DENV serotype was determined by the size of the amplified fragment. The minimum infection rate (MIR) was estimated to compare the virus infection rates in the mosquitoes collected from different sampling points. MIR was calculated for each sub-district according to the standard formula: (the number of DENV-positive mosquito pools/the total number of mosquitoes tested) $\times 1,000(11)$.

Between January 2008 and December 2015, 16,605 female Aedes mosquitoes were collected from the 15 sub-districts of Surabaya, encompassing all the geographical zones (Fig. 1). Ae. aegypti was the dominant species $(90.9 \%)$, whereas few Ae. albopictus were collected $(9.1 \%)$, indicating that Ae. aegypti was the principal dengue vector in Surabaya. Due to its close association with humans, this species has played a major role in the worldwide emergence of dengue for the last 50 years (1).

Two hundred ninety six pools and 34 pools were prepared from 15,099 Ae. aegypti and 1,506 Ae. albopictus, respectively, collected from the sample sites (Table 1). Of the 296 Ae. aegypti pools assayed, 109 $(36.8 \%, 109 / 296)$ showed RT-PCR positivity; wherein 57 pools $(52.3 \%, 57 / 109)$ were positive for DENV-1, 44 pools $(40.4 \%, 44 / 109)$ were positive for DENV-2, 3 pools $(2.8 \%, 3 / 109)$ were positive for DENV-3, and 5 pools $(4.6 \%, 5 / 109)$ were positive for DENV-4. Of the 34 Ae. albopictus pools assayed, only 1 was positive for DENV-1. DENV-1 and DENV-2 were the most com-

Table 1. Identification of DENV serotypes detected from Aedes spp. in Surabaya

\begin{tabular}{|c|c|c|c|c|c|c|c|c|c|}
\hline \multirow[b]{2}{*}{ Region } & \multirow[b]{2}{*}{ Sub-distinct } & \multicolumn{3}{|c|}{ Ae. aegypti } & \multicolumn{3}{|c|}{ Ae. albopictus } & \multicolumn{2}{|c|}{ Detected DENV serotype ${ }^{1)}$} \\
\hline & & $\begin{array}{c}\text { Female } \\
\text { mosquito } \\
\text { (total pool) }\end{array}$ & $\begin{array}{l}\text { Positive } \\
\text { pool }\end{array}$ & $\mathrm{MIR}^{2)}$ & $\begin{array}{c}\text { Female } \\
\text { mosquito } \\
\text { (total pool) }\end{array}$ & $\begin{array}{l}\text { Positive } \\
\text { pool }\end{array}$ & MIR & $\begin{array}{c}\text { Ae. aegypti } \\
\text { (positive pool) }\end{array}$ & $\begin{array}{l}\text { Ae. albopictus } \\
\text { (positive pool) }\end{array}$ \\
\hline \multirow[t]{2}{*}{ Central } & Tegalsari & $856(17)$ & 8 & 9.3 & 0 & 0 & 0 & D1 (6), D4 (2) & - \\
\hline & Simokerto & 978 (19) & 6 & 6.1 & 0 & 0 & 0 & D1 (3), D2 (2), D4 (1) & - \\
\hline \multirow[t]{2}{*}{ West } & Sukomanunggal & $1,038(20)$ & 5 & 4.8 & $382(7)$ & 0 & 0 & D1(2), D2 (3) & - \\
\hline & Asemrowo & $622(12)$ & 2 & 3.2 & 0 & 0 & 0 & D1 (2) & - \\
\hline \multirow[t]{2}{*}{ North } & Kenjeran & $826(16)$ & 1 & 1.2 & $80(4)$ & 0 & 0 & D2 (1) & - \\
\hline & Bulak & $817(16)$ & 6 & 7.3 & 0 & 0 & 0 & D1 (3), D2 (3) & - \\
\hline \multirow[t]{4}{*}{ East } & Tambaksari & $1,643(32)$ & 19 & 11.6 & $480(9)$ & 0 & 0 & D1 (9), D2 (8), D3 (1), D4 (1) & - \\
\hline & Gubeng & $1,405(28)$ & 15 & 10.6 & 0 & 0 & 0 & D1 (7), D2 (8) & - \\
\hline & Sukolilo & $636(12)$ & 4 & 6.3 & 0 & 0 & 0 & D1 (3), D2 (1) & - \\
\hline & Mulyorejo & $980(19)$ & 6 & 6.1 & $240(6)$ & 0 & - & D1 (4), D2 (2) & - \\
\hline \multirow[t]{4}{*}{ South } & Dukuh Pakis & 968 (19) & 3 & 3.0 & $124(3)$ & 0 & - & D1 (3) & - \\
\hline & Sawahan & $2,163(43)$ & 24 & 11.0 & $180(4)$ & 1 & 5.5 & D1 (10), D2 (11), D3 (2), D4 (1) & D1 (1) \\
\hline & Wonocolo & $864(17)$ & 4 & 4.6 & 0 & 0 & 0 & D1 (3), D2 (1) & - \\
\hline & Total & $15,099(296)$ & 109 & 7.2 & $1,506(34)$ & 1 & 0.7 & D1 (57), D2 (44), D3 (3), D4 (5) & D1 (1) \\
\hline
\end{tabular}

\footnotetext{
1): No co-infection case was detected. DENV-1, -2, -3, and -4 were abbreviated by D1, D2, D3, and D4, respectively.
}

2): Minimum infection rate $(\mathrm{MIR})=($ No. of positive pools $/$ No. of mosquitoes $) \times 1,000$. 
monly detected serotypes in most of the sub-districts, although the sampling points were located far from each other (Fig. 1). Aedes mosquitoes do not migrate over large areas and are generally limited to a radius of $150 \mathrm{~m}$ from their breeding site (12). It was revealed that human movement, instead of mosquito movement might have contributed to the dissemination of DENV in Surabaya, as reported in Rio de Janeiro, Brazil (13).

The MIRs for Ae. aegypti and Ae. albopictus in each sub-district area are shown in Table 1. The average MIR for Ae. aegypti in the various sub-districts of Surabaya was 7.2 per 1,000 mosquitoes (ranged between 1.2 and 11.6 per 1,000 mosquitoes), whereas it was 0.7 per 1,000 mosquitoes (ranged between 0 and 5.5 per 1,000 mosquitoes) for Ae. albopictus. These MIR values were lower than that of the previous findings, such as those from Venezuela (16.0 per 1,000 mosquitoes) (14) and Singapore (57.6 per 1,000 mosquitoes) (15). Many factors might have contributed to the low MIRs obtained in this study. Mosquito collections were conducted late (1-2 weeks after the outbreak), and fogging insecticide might have also reduced the number of infected mosquitoes collected during this study.

Chronological detection data showed the dominance of DENV-2 in 2008, followed by DENV-1 dominance between 2009 and 2012 (Fig. 2). In 2013, although all DENV serotypes were detected, DENV-2 was dominant, indicating a serotype shift, which also continued till 2014. In 2015, DENV-1 was dominant again, despite the detection of all the 4 DENV serotypes, indicating another serotype shift. We have previously reported the sequential changes in the predominant DENV serotype isolated from the dengue patient sera in this area; i.e., from DENV-2 to DENV-1 in November 2008, and from DENV-1 to DENV-2 in July $2013(8,9)$. Taken together, the predominant DENV serotypes detected in the mosquitoes were generally consistent with those detected in human sera. A previous study reported that the DENV serotype shift was associated with a dengue outbreak (9). The surveillance of infected mosquitoes with DENV may provide an early warning sign for assessing the risk of a dengue outbreak.

A phylogenetic analysis might have provided inter-

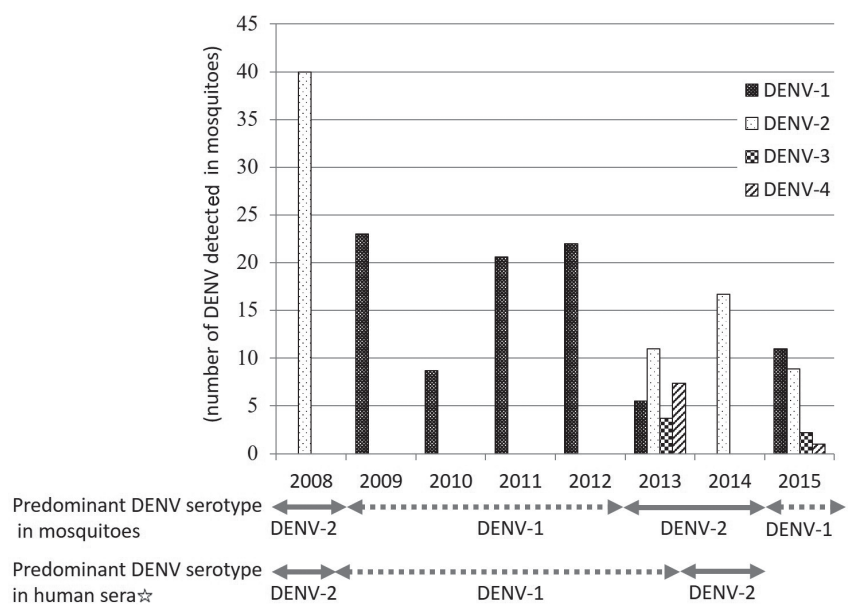

Fig. 2. Chronological data on DENV detected from Aedes mosquitoes collected in Surabaya between 2008 and 2015. $i s$ The information of predominant DENV serotype in human sera was retrieved from the previous studies $(8,9)$. esting insights, however, it was not conducted in the present study due to the failure of PCR. Phylogenetic analysis should be conducted in future to compare the DENVs circulating in the different sub-districts as well as in the mosquitoes and humans.

In conclusion, this study showed the sequential shifts of the predominant DENV serotype in mosquitoes, which were generally consistent with that in human sera. Monitoring of the virus circulation in mosquitoes will enable us to predict the risk of a dengue outbreak, and, will hence contribute to identifying the locations, which will require prevention and control measures.

Acknowledgments We would like to thank the Heads of the Surabaya Health Office and the owners of the subject houses for their permission for this study. This work was supported in part by the program of the Japan Initiative for Global Research Network on Infectious Diseases (J-GRID) from the Ministry of Education, Culture, Sport, Science and Technology in Japan and the Japan Agency for Medical Research and Development (AMED); the Center of Excellence (COE) Program by the Ministry for Research and Technology (RISTEK) of Indonesia; and Research MANDAT Airlangga University.

Conflict of interest None to declare.

\section{REFERENCES}

1. World Health Organization (WHO). Global Strategy for dengue prevention and control, 2012-2020. Available at <http://www.who. $\mathrm{int} /$ denguecontrol/resources/9789241504034/en/>. Accessed July 20, 2016 .

2. WHO. Handbook of clinical management of dengue. Available at <http://www.who.int/denguecontrol/9789241504713/en/>. Accessed July 20, 2016.

3. Kutsuna S, Kato Y, Moi ML, et al. Autochthonous dengue fever, Tokyo, Japan, 2014. Emerg Infect Dis. 2015;21:517-20.

4. Lambrechts L, Fansiri T, Pongsiri A, et al. Dengue-1 virus clade replacement in Thailand associated with enhanced mosquito transmission. J Virol. 2012;86:1853-61.

5. Vasilakis N, Deardorff ER, Kenney JL, et al. Mosquitoes put the brake on arbovirus evolution: experimental evolution reveals slower mutation accumulation in mosquito than vertebrate cells. PLoS Pathog. 2009;5:e1000467.

6. Duong V, Simmons C, Gavotte L, et al. Genetic diversity and lineage dynamic of dengue virus serotype 1 (DENV-1) in Cambodia. Infect Genet Evol. 2013;15:59-68.

7. Karyanti MR, Uiterwaal CS, Kusriastuti R, et al. The changing incidence of dengue haemorrhagic fever in Indonesia: a 45-year registry-based analysis. BMC Infect Dis. 2014;14:412.

8. Kotaki T, Yamanaka A, Mulyatno KC, et al. Continuous dengue type 1 virus genotype shifts followed by co-circulation, clade shifts and subsequent disappearance in Surabaya, Indonesia, 2008-2013. Infect Genet Evol. 2014;28:48-54

9. Yamanaka A, Mulyatno KC, Susilowati H, et al. Displacement of the predominant dengue virus from type 2 to type 1 with a subsequent genotype shift from IV to I in Surabaya, Indonesia 2008-2010. PLoS One. 2011;6:e27322.

10. Lanciotti RS, Calisher CH, Gubler DJ, et al. Rapid detection and typing of dengue viruses from clinical samples by using reverse transcriptase-polymerase chain reaction. J Clin Microbiol. 1992;30:545-51.

11. Gu W, Lampman R, Novak RJ. Assessment of arbovirus vector infection rates using variable size pooling. Med Vet Entomol. 2004;18:200-4.

12. Huber K, Loan LL, Chantha N, et al. Human transportation influences Aedes aegypti gene flow in Southeast Asia. Acta Trop. 2004;90:23-9.

13. Honório NA, Nogueira RM, Codeço CT, et al. Spatial evaluation and modeling of dengue seroprevalence and vector density in Rio de Janeiro, Brazil. PLoS Negl Trop Dis. 2009;3:e545.

14. Urdaneta L, Herrera F, Pernalete M, et al. Detection of dengue viruses in field-caught Aedes aegypti (Diptera: Culicidae) in 
Serotyping of DENVs from Mosquitoes in Indonesia

Maracay, Aragua state, Venezuela by type-specific polymerase chain reaction. Infec Genet Evol. 2005;5:177-84.

15. Chow VT, Chan YC, Yong R, et al. Monitoring of dengue viruses in field-caught Aedes aegypti and Aedes albopictus mosquitoes by a type-specific polymerase chain reaction and cycle sequencing. Am J Trop Med Hyg. 1998;58:578-86. 